\title{
Cytoreductive Surgery and Hyperthermic Intraperitoneal Chemotherapy With Mitomycin C Used for Colorectal Peritoneal Carcinomatosis
}

\author{
Seung Jae Roh, Sung Chan Park, Jaehee Choi, Joon Sang Lee, Dong Woon Lee, Chang Won Hong, \\ Kyung Su Han, Hyoung Chul Park, Dae Kyung Sohn, Jae Hwan Oh \\ Center for Colorectal Cancer, Research Institute and Hospital, National Cancer Center, Goyang, Korea
}

Purpose: This study aimed to assess the evaluation of clinical outcomes and consequences of complications after cytoreductive surgery (CRS) and hyperthermic intraperitoneal chemotherapy (HIPEC) for the peritoneal carcinomatosis (PC) from colorectal cancer.

Methods: A total 26 patients underwent CRS and HIPEC for PC from colorectal cancer between March 2009 and April 2018. All the patients underwent CRS with the purpose of complete or near-complete cytoreduction. Intraoperative HIPEC was performed simultaneously after the CRS. Mitomycin C was used as chemotherapeutic agent for HIPEC.

Results: Median disease-free survival was 27.8 months (range, 13.4-42.2 months). Median overall survival was 56.0 months (range, 28.6-83.5 months). The mean peritoneal cancer index (PCI) was $8.73 \pm 5.54$. The distributions thereof were as follows: PCI <10, 69.23\%; PCI 10-19, 23.08\%; and PCI $\geq 20,7.69 \%$. The completeness of cytoreduction was $96.2 \%$ of patients showed CC- 0 , with $3.8 \%$ achieved CC- 1 . The mean operation time was 8.5 hours, and the mean postoperative hospital stay was 21.6 days. The overall rate of early postoperative complications was $88.5 \%$; the rate of late complications was $34.6 \%$. In the early period, most complications were grades I-II complications (65.4\%), compared to grades III-V (23.1\%). All late complications, occurring in $7.7 \%$ of patients, were grades III-V. There was no treatment-related mortality. Conclusion: Although the complication rate was approximately $88 \%$, but the rate of severe complication rate was low. In selective patients with peritoneal recurrence, more aggressive strategies for management, such as CRS with HIPEC, were able to be considered under the acceptable general condition and life-expectancy.

Keywords: Colorectal neoplasms; Peritoneal carcinomatosis; Cytoreductive surgery; Hyperthermic intraperitoneal chemotherapy

\section{INTRODUCTION}

Peritoneal metastasis of colorectal cancer is the fourth most common recurrence site in all colorectal cancer patients, occurring in

Received: February 18, 2019 • Accepted: April 30, 2019

Correspondence to: Sung Chan Park, M.D.

Center for Colorectal Cancer, Research Institute and Hospital, National

Cancer Center, 323 Ilsan-ro, Ilsandong-gu, Goyang 10408, Korea

Tel: +82-32-920-1041, Fax: +82-32-920-1148

E-mail: sungchan@ncc.re.kr

ORCID: https://orcid.org/0000-0003-3949-7862

(C) 2020 The Korean Society of Coloproctology

This is an open-access article distributed under the terms of the Creative Commons Attribution NonCommercial License (https://creativecommons.org/licenses/by-nc/4.0) which permits unrestricted non-

commercial use, distribution, and reproduction in any medium, provided the original work is properly cited. about $10 \%$ of colorectal cancer patients [1]. This is related to the poor prognosis of the patient and the 5-year survival rate is reported to be about $20 \%-30 \%$ despite treatment with chemotherapy. After cytoreductive surgery (CRS) and hyperthermic intraperitoneal chemotherapy (HIPEC) was first introduced by Sugarbaker et al. [2, 3], several studies have reported that the 5-year survival rate of patients undergoing CRS and HIPEC is over $45 \%$ [4-6].

However, CRS and HIPEC are technically challenging and require a well-trained team, with high postoperative complications and a long learning curve compared to other surgeries [7-9]. Although CRS and HIPEC have been extensively used in Western Europe and US treatments, they are also known to have high morbidity in centers with experienced surgeons. In the United 
States, about $10 \%$ of patients undergoing CRS and HIPEC undergo reoperation and the incidence of major complications is reported to be approximately 33\% [10]. Complications related to CRS can be caused by the long operation time and hemodynamic changes due to the resection of multiple sites. CRS and HIPEC may increase the risk of surgical complications and toxicity, which may lead to postoperative bleeding, anastomosis leak, bowel perforation wound dehiscence, etc. HIPEC may lead to nephrotoxicity or hepatotoxicity [7].

The purpose of this study was to evaluate the safety and efficacy for patients with peritoneal metastasis after examining clinical prognosis and postoperative complications on patients underwent CRS and HIPEC in our hospital.

\section{METHODS}

\section{Preoperative Diagnosis and Patient Selection}

From February 2008 to April 2018, CRS and HIPEC were performed in 26 patients with peritoneal metastasis or pseudomyxoma peritonei in colorectal cancer and retrospectively analyzed. Patients underwent thoracic and abdominal computed tomography and esophagogastroduodenoscopy and colonoscopy to confirm peritoneal metastasis and other metastases before surgery. When computed tomography was difficult to diagnose or suspicion of nonabdominal metastasis, positron emission tomographycomputed tomography was also considered. Inclusion criteria were defined as patients who were predicted to be able to undergo complete resection due to only metastasis within the abdominal cavity confirmed by preoperative computed tomography or positron emission tomography-computed tomography, among patients with suspected peritoneal metastasis in histologically proven colorectal cancer. The exclusion criteria were patients whose peritoneal metastases were unresectable or underwent emergency surgery, patients with extraperitoneal metastases, patients with unresectable hepatic metastases, and patients with poor overall system status at 2 or more points in the Eastern Cooperative Oncology Group. This study was approved by the Institutional Review Board (IRB) of the National Cancer Center (NCC2019-0016). And informed consent was not obtained because this was a retrospective study using clinical practice data.

\section{Data Forms}

Patient characteristics, history, peritoneal metastasis, complications, short follow-up data were studied retrospectively. Peritoneal cancer index score was measured by abdominal exploration during surgery. Abdominal cavity was divided into 13 compartments and subdivided into $0-3$ points according to the size of peritoneal metastasis ( 0 points, absence of tumor; 1 point, tumor less than $0.5 \mathrm{~cm} ; 2$ points, tumor from $0.5 \mathrm{~cm}$ to $5 \mathrm{~cm}$; and 3 points, tumor larger than $5 \mathrm{~cm}$ ). The scores were marked from 0 to 39 in total [11]. Peritoneal cancer index score was divided into 3 groups according to the score, and was divided into less than 10 points, be- tween 10 points and 19 points, and more than 20 points. Completeness of cytoreduction after surgery was subdivided according to the size of residual tumor (CC-0, complete removal of visible tumor; CC-1, remnant tumor less than $0.25 \mathrm{~cm}$; CC-2, residual tumor between $0.25 \mathrm{~cm}$ and $2.5 \mathrm{~cm}$; and CC-3, visible tumor larger than $2.5 \mathrm{~cm}$ in diameter). Complications were classified into 5 grades according to the Clavien-Dindo grade classification. Class 0 to II were classified as mild cases and grade III and above were classified as serious complications.

\section{CRS and HIPEC Procedure}

In case of patients with synchronous peritoneal metastasis, primary tumor resection was performed at the same time. In case of patients with metachronous peritoneal metastasis, patients with metastasis during the postoperative chemotherapy or follow-up of the primary tumor underwent resection after receiving full explanation and consent. As suggested by Sugarbaker, CRS was carried out to remove the cancer cells by mechanical means through the naked eye and minimize the peritoneal cancer index score [12]. Peritoneal resection was performed selectively according to the location of peritoneal metastasis, such as anterior peritonectomy (right and left), Epigastric peritonectomy, right subdiaphragmatic peritonectomy, left subdiaphragmatic peritonectomy, greater omentectomy, lesser omentectomy, pelvic peritonectomy, cholecystectomy \& resection of the omental bursa, etc.

HIPEC was prepared by mixing mitomycin C with $15 \mathrm{mg} / \mathrm{m}^{2}$ of body surface area in $4,500 \mathrm{~mL}$ of physiological saline. The mixed solution was circulated through a HIPEC pump (The Belmont Hyperthermic Pump) at a rate of 800 to $1,000 \mathrm{~mL} / \mathrm{min}$ for 90 minutes while maintaining the $42^{\circ} \mathrm{C}$ to $43^{\circ} \mathrm{C}$. The patient's central body temperature, inflow temperature, and outflow temperature were checked every 5 minutes, and the target temperature was controlled through the inlet temperature of the HIPEC pump. All patients underwent more than one day of follow-up in intensive care unit. When the vital sign was stable and there was no change in the drainage tube or clinical examination results, patients were transferred to the general ward. Most of the Levin tubes were removed immediately after surgery or the next day. Water intake started the day after surgery. All patients underwent a total of 4 drainage tubes in the pelvic cavity and bilateral diaphragmatic space after the operation. Abdominal computed tomography was performed on the 7th postoperative day to confirm the absence of abnormalities and tubes were removed.

\section{Statistical Analysis}

Statistical analysis was performed using IBM SPSS Statistics ver. 22.0 (IBM Co., Armonk, NY, USA). Categorical variables are described as frequency and percentage, and continuous variables as mean and standard error, minimum and maximum values. Crossover analysis was used for the comparison of complications, and a P-value less than 0.05 was considered statistically significant. 


\section{RESULTS}

A total of 26 patients underwent CRS and HIPEC (Table 1). The average age of the patients was 55.3 years, $35 \%$ were males and $65 \%$ were females. Body mass index was $22.32 \pm 3.97 \mathrm{~kg} / \mathrm{m}^{2}$ (range, $17.8-32.3 \mathrm{~kg} / \mathrm{m}^{2}$ ). American Society of Anesthesiologists physical status classification was I in $42.3 \%$, II in $53.8 \%$ and III in $3.8 \%$. The primary tumor sites were most common in sigmoid colon, synchronous peritoneal metastasis in 9 patients (34.6\%) and metachronous peritoneal metastasis in 17 patients (65.4\%). The preoperative chemotherapy was used in 17 patients (65.4\%). Twelve patients among them underwent surgery in the progres-

Table 1. Demographics and characteristics of patients

\begin{tabular}{|c|c|}
\hline Category & №. $(\%)$ \\
\hline Age & $55.27 \pm 11.06(35-69)$ \\
\hline \multicolumn{2}{|l|}{ Sex } \\
\hline Male & $9(34.6)$ \\
\hline Female & $17(65.4)$ \\
\hline Body mass index $\left(\mathrm{kg} / \mathrm{m}^{2}\right)$ & $22.32 \pm 3.97(17.8-32.3)$ \\
\hline \multicolumn{2}{|l|}{ ASA PS classification } \\
\hline I & $11(42.3)$ \\
\hline$\|$ & $14(53.8)$ \\
\hline III & $1(3.8)$ \\
\hline \multicolumn{2}{|l|}{ Primary cancer } \\
\hline Ascending colon cancer & $4(15.4)$ \\
\hline Hepatic flexure cancer & $1(3.8)$ \\
\hline Transverse colon cancer & $1(3.8)$ \\
\hline Descending colon cancer & $2(7.7)$ \\
\hline Sigmoid colon cancer & $8(30.8)$ \\
\hline Rectal cancer & $6(23.1)$ \\
\hline Appendiceal cancer & $4(15.4)$ \\
\hline \multicolumn{2}{|l|}{ Previous abdominal surgery } \\
\hline Yes & $21(80.8)$ \\
\hline No & 5 (19.2) \\
\hline \multicolumn{2}{|l|}{ Previous colorectal cancer surgery } \\
\hline Yes & $17(65.4)$ \\
\hline Cecectomy & 1 \\
\hline Right hemicolectomy & 5 \\
\hline Left hemicolectomy & 2 \\
\hline Anterior resection & 5 \\
\hline Low anterior resection & 4 \\
\hline Time interval since last surgery (mo) & $24.56 \pm 10.9(1-50)$ \\
\hline No & $7(26.9)$ \\
\hline
\end{tabular}

(Continued to the next) sion disease state during chemotherapy, 5 underwent surgery in stable disease state after finding peritoneal metastasis and chemotherapy. Of the 9 patients with synchronous peritoneal metastasis, 1 patient who underwent stenting with colonic obstruction, and 1 patient who was transferred to our hospital after chemotherapy in other hospitals, the remaining 7 patients did not undergo neoadjuvant chemotherapy. Preoperative chemotherapy was performed in 15 of 17 patients with metachronous peritoneal metastasis patients.

Some patients had accompanied resection during surgery due to metastasis to the other organs; 2 had liver metastasis and 1 had spleen. Histopathologic type was adenocarcinoma in 15, infiltrating cell carcinoma in 1, and mucinous carcinoma in 10. Preoperative carcinoembryonic antigen was $192.13 \pm 812.33 \mathrm{ng} / \mathrm{mL}$ (range, $1.0-4,160.6 \mathrm{ng} / \mathrm{mL}$ ) and it was $7.25 \pm 17.23 \mathrm{ng} / \mathrm{mL}$ (range, $0.6-$ $82.7 \mathrm{ng} / \mathrm{mL}$ ) after 1 of operation.

The peritoneal cancer index score of the patients was as follows; less than 10 points in 18 patients (69\%), $10-19$ points in 6 patients, and more than 20 points in 2 patients (Table 2). The CRS completion score (CC score) was 0 in all except 1 patient. In the case of patient with 1 score, residual tumor occurred due to severe

Table 1. Continued

\begin{tabular}{lc}
\hline Category & No. (\%) \\
\hline Presentation of peritoneal carcinomatosis & $8(30.8)$ \\
Synchronous & $17(65.4)$ \\
Metachronous & \\
Previous chemotherapy & $17(65.4)$ \\
Yes & $9(34.6)$ \\
1st line & $6(23.1)$ \\
2nd line & $2(7.7)$ \\
3rd line & $9(34.6)$ \\
No & \\
Synchronous organ metastasis & $2(7.7)$ \\
Liver & $1(3.8)$ \\
Spleen & \\
Histology of primary colorectal cancer & $3(11.5)$ \\
WD & $9(34.6)$ \\
MD & $3(11.5)$ \\
PD & $1(3.8)$ \\
Signet ring cell & $10(38.5)$ \\
Mucinous & $192.13 \pm 812.33(1.0-4,160.6)$ \\
Preop CEA (ng/mL) & $7.25 \pm 17.23(0.6-82.7)$ \\
\hline Postop CEA (<7 days) (ng/mL) & \\
\hline
\end{tabular}

Values are presented as number (\%) or mean \pm standard deviation (range). ASA PS, American Society of Anesthesiologists physical status; WD, well differentiated; $\mathrm{MD}$, moderately differentiated; PD, poorly differentiated; CEA, carcinoembryonic antigen. 
Volume 36, Number 1, 2020

adhesions.

Operative transfusion was performed in 8 patients. The average operation time was 507 minutes and blood loss was $652 \mathrm{~mL}$ on average. All patients underwent surgery. Total 3 ostomies were performed: 1 case for permanent ileostomy in patient underwent total proctocolectomy, 1 case for temporary ileostomy in patient underwent low anterior resection, and 1 case for permanent colostomy in patient underwent abdominoperineal resection.

Table 2. Intraoperative outcomes

\begin{tabular}{|c|c|}
\hline Variable & No. $(\%)$ \\
\hline \multicolumn{2}{|l|}{ PCl score } \\
\hline$<10$ & $18(69.23)$ \\
\hline $10-19$ & $6(23.08)$ \\
\hline$\geq 20$ & $2(7.69)$ \\
\hline Mean \pm SD & $8.73 \pm 5.54$ \\
\hline \multicolumn{2}{|l|}{ CC score } \\
\hline 0 & 25 (96.2) \\
\hline 1 & $1(3.8)$ \\
\hline 2 & $0(0)$ \\
\hline 3 & $0(0)$ \\
\hline \multicolumn{2}{|l|}{ Intraoperative transfusion } \\
\hline Yes & $8(30.8)$ \\
\hline No & 18 (69.2) \\
\hline Operative time (yr) & $507.69 \pm 152.46(285-950)$ \\
\hline Estimated blood loss (mL) & $651.92 \pm 786.06(50-3,000)$ \\
\hline \multicolumn{2}{|l|}{ No. of anastomosis } \\
\hline 0 & $3(11.5)$ \\
\hline 1 & $12(43.2)$ \\
\hline 2 & $7(26.9)$ \\
\hline 3 & $4(15.4)$ \\
\hline \multicolumn{2}{|l|}{ Combined resection organ } \\
\hline Liver (tumorectomy) & $2(7.7)$ \\
\hline Gall bladder & $3(11.5)$ \\
\hline Stomach & $3(11.5)$ \\
\hline Spleen & 7 (26.9) \\
\hline Uterus and ovary & $7(26.9)$ \\
\hline Bladder & $1(3.8)$ \\
\hline \multicolumn{2}{|l|}{ Fecal diversion } \\
\hline None & $23(88.5)$ \\
\hline Ileostomy & $2(7.7)$ \\
\hline Colostomy & $1(3.8)$ \\
\hline
\end{tabular}

Values are presented as number (\%) or mean \pm standard deviation (range) unless otherwise indicated.

$\mathrm{PCl}$, peritoneal cancer index; SD, standard deviation; CC, completeness of cytoreduction.
The average postoperative hospital stay was 21 days (Table 3), and they started to eat porridge within an average of 1 week. Postoperative chemotherapy was recommended for all patients, but it was performed in 12 patients due to complication or rejection and started after average 52 days after surgery (range, 31-105 days). And 5 patients were treated coadministration with Bevacizumab and FOLFIRI.

Postoperative complications occurred in $88.5 \%$ in early period within 30 days and in $34.6 \%$ in late period (Table 4). Complications were recorded in duplicate and more than the total number of patients, 26. In early period, 3 patients had no complication and 17 patients had grade I to II complications. Among them, 9 (34.6\%) had ileus, which was the most frequent complication. Severe complications of grade III or higher occurred in 6 patients and most were associated with postoperative wound infection or suture. One patient underwent delayed wound closure due to deep incisional infection, 1 patient underwent percutaneous drainage due to deep organ infection, and 2 underwent primary closure with wound dehiscence. One patient had septicemia due to colonic-rectal anastomosis leaks during low anterior resection of CRS but recovered after percutaneous drainage and controlled fistula. There was no death. The complications after 30 days of operation were 9 patients (34.6\%), 2 intestinal obstruction due to intestine adhesions, 3 dysuria, 1 erectile dysfunction, 1 pelvic abscess, 1 ureteral stenosis, 1 rectal stenosis. There were 2 patients with serious complications.

With regard to postoperative complications, 6 patients with severe complications were compared to 20 patients without complications or mild complications. The factors associated with complications were investigated (Table 5). Patient characteristics and

Table 3. Postoperative clinical outcomes

\begin{tabular}{lc}
\hline Category & Value \\
\hline Length of ICU stay (day) & $0.92 \pm 0.56(0-2)$ \\
Length of postoperative day & $21.58 \pm 13.51(9-73)$ \\
Days to 1st sips of water & $1.80 \pm 1.39(1-6)$ \\
Days to 1st soft diet & $7.19 \pm 3.05(4-16)$ \\
Days to removal of Levin tube & $0.85 \pm 1.32(0-6)$ \\
Days to removal of JP drain & $15.42 \pm 13.46(7-72)$ \\
Postoperative chemotherapy & \\
Yes & $12(46.2)$ \\
No & $14(53.8)$ \\
Regimen of 1st postoperative chemotherapy & \\
Bevacizumab + FOLFIRI & $5(19.2)$ \\
Bevacizumab + FOLFOX & $2(7.7)$ \\
FOLFOX & $4(15.4)$ \\
Capecitabine & $1(3.3)$ \\
\hline
\end{tabular}

Values are presented as mean \pm standard deviation (range) or number (\%). ICU, intensive care unit; JP, Jackson-Pratt. 


\section{Coloproctology seung Jae Roh, et all}

Table 4. Postoperative complications $(\mathrm{n}=26)$

\begin{tabular}{|c|c|}
\hline Clavien-Dindo grade \& complications & №. $(\%)$ \\
\hline Early postoperative complication (spostoperative 30 days) & $23(88.5)$ \\
\hline Grade I & $19(73.1)$ \\
\hline lleus & 9 \\
\hline Urinary retention & 7 \\
\hline Hydrocecle & 1 \\
\hline Pleural effusion & 1 \\
\hline Chyle & 1 \\
\hline Grade ॥ & $4(15.4)$ \\
\hline Wound seroma & 2 \\
\hline Urinary tract infection & 1 \\
\hline Deep vein thrombosis & 1 \\
\hline Grade IIla & $4(15.4)$ \\
\hline Wound dehiscence & 2 \\
\hline Deep incisional infection & 1 \\
\hline Deep organ infection & 1 \\
\hline Grade IIIb & $2(7.7)$ \\
\hline Anastomotic leak & 1 \\
\hline Urinary leak from Bladder & 1 \\
\hline \multicolumn{2}{|l|}{ Grade IV } \\
\hline Sepsis & $1(3.8)$ \\
\hline \multicolumn{2}{|l|}{ Grade V } \\
\hline- & - \\
\hline Late postoperative complication (>postoperative 30 days) & $9(34.6)$ \\
\hline Grade I & $5(19.2)$ \\
\hline Urinary difficulty & 3 \\
\hline lleus & 2 \\
\hline Grade II & $2(7.7)$ \\
\hline Impotence & 1 \\
\hline Pelvic abscess & 1 \\
\hline \multicolumn{2}{|l|}{ Grade IIla } \\
\hline Ureter stricture & $1(3.8)$ \\
\hline \multicolumn{2}{|l|}{ Grade Illb } \\
\hline Rectovaginal fistula & $1(3.8)$ \\
\hline \multicolumn{2}{|l|}{ Grade IV } \\
\hline- & - \\
\hline Grade V & \\
\hline
\end{tabular}

outcomes were compared. There was a significant difference in the presence of transfusion during surgery $(\mathrm{P}=0.004)$. There was no difference in the amount of blood loss during the operation between the mild and severe complications. In the mild complica- tion group only red blood cells (RBC) or fresh frozen plasma (FFP) was transfused. In the severe complication group, 1 patient was injected platelet only, 1 patient was in RBC only, and 3 patients were injected RBC and FFP at the same time Operative transfusion was performed in 8 patients. One patient had no complications. Of 7 patients with complications, 5 patients had severe complications. As mind complication, there were 3 cases of urinary retention. Two cases of ileus, 1 case of pleural effusion, hydrocele, etc. Severe complications included septicemic due to anastomosis leak, deep incisional infection, deep organ infection, wound dehiscence, urinary leak of bladder, for one case respectively.

Among 26 CRS and HIPEC patients, 15 patients had recurrence and 6 patients died. The median follow-up period was 15 months (range, 1-100 months). The median disease-free survival was 27.8 months (range, 13.4-42.2 months). The median overall survival was 56.0 months (range, 28.6-83.5 months) for 3 deaths except for 3 patients who were discharged to other hospitals or lost to follow-up. The cancer-specific survival rates of 2 and 3 years were $57 \%$ and $36 \%$, respectively.

\section{DISCUSSION}

The treatment of patients with metastatic colorectal cancer has been continuously studied. In patients with colorectal cancer with unresectable metastases, systemic chemotherapy has been shown to increase median survival to more than 24 months [13], and the resection of metastatic masses in the lung and liver also increases survival rate [14]. As with these reasons, CRS and HIPEC of peritoneal metastatic colorectal cancer are one of the treatment options for patients with colorectal cancer metastasis and has increased the survival rate $[4-10,12]$.

However, the criteria for the selection of patients who can perform CRS and HIPEC have not been studied yet because sufficient clinical randomized trial has not been done yet. Goéré et al. [15] retrospectively reviewed the patients who underwent CRS and intraperitoneal chemotherapy and found that the 5-year survival rate was significantly higher when PCI score was less than 10. Elias et al. [16] reported that PCI score was independent prognostic factor for overall survival. In this study, the average postoperative PCI score was 8.73 points, and 8 patients $(30.1 \%)$ had a score of 10 points or more. The CC score was reported to be an important prognostic factor in patients undergoing CRS and HIPEC as well as the PCI score [16, 17]. In this study, all patients except for 1 (3.8\%) showed CC-0, and neither PCI score nor CC score was significantly correlated with survival.

In this study, mean operation time was 507 minutes (range, 285-950 minutes) and mean hospital stay was 21.6 days (range, 9-73 days). Polanco et al. [18] showed that the mean operation time was 430 minutes in 370 patients with CRS and HIPEC and 15.86 days in mean hospital stay, which is shorter than the results of this study. However, in the case of Kusamura et al. [19] while 
Table 5. Factors associated severe early complications ( $\leq$ postoperative 30 days)

\begin{tabular}{|c|c|c|c|}
\hline Variable & $<$ CIII $(n=20)$ & $\geq$ CIII $(n=6)$ & P-value \\
\hline Age (yr) & $54.45 \pm 9.83$ & $58.00 \pm 15.26$ & 0.609 \\
\hline Sex & & & 1.000 \\
\hline Male & $7(35.0)$ & $2(33.3)$ & \\
\hline Female & $13(65.0)$ & $4(66.7)$ & \\
\hline Body mass index $\left(\mathrm{kg} / \mathrm{m}^{2}\right)$ & $23.67 \pm 3.74$ & $22.17 \pm 4.87$ & 0.428 \\
\hline ASA PS classification & & & 0.232 \\
\hline I & $10(50.0)$ & $1(16.7)$ & \\
\hline$\|$ & $9(45.0)$ & $5(83.3)$ & \\
\hline$\|$ & $1(5.0)$ & $0(0)$ & \\
\hline Primary cancer location & & & 1.000 \\
\hline Right colon & $8(40.0)$ & $2(33.3)$ & \\
\hline Left colon & $7(35.0)$ & $3(50.0)$ & \\
\hline Rectum & $5(25.0)$ & $1(16.7)$ & \\
\hline Presentation of peritoneal carcinomatosis & & & 1.000 \\
\hline Synchronous & $8(40.0)$ & $2(33.3)$ & \\
\hline Metachronous & $12(60.0)$ & $4(66.7)$ & \\
\hline Histology & & & 0.065 \\
\hline WD/MD & $7(35.0)$ & $5(83.3)$ & \\
\hline PD/signet/mucinous & $13(65.0)$ & $1(16.7)$ & \\
\hline Previous abdominal surgery & & & 1.000 \\
\hline Yes & $16(80.0)$ & $5(83.3)$ & \\
\hline No & $4(20.0)$ & $1(16.7)$ & \\
\hline Preoperative CEA (ng/mL) & $237.67 \pm 926.49$ & $40.33 \pm 40.15$ & 0.354 \\
\hline Postoperative CEA (7 days) (ng/mL) & $7.64 \pm 20.21$ & $6.23 \pm 4.41$ & 0.870 \\
\hline PCl score & $9.00 \pm 5.94$ & $7.83 \pm 4.26$ & 0.660 \\
\hline$<10$ & $15(75.0)$ & $4(66.7)$ & 0.529 \\
\hline$\geq 10$ & $5(25.0)$ & $2(33.3)$ & \\
\hline Intraoperative transfusion & & & 0.004 \\
\hline Yes & $3(15.0)$ & $5(83.3)$ & \\
\hline No & $17(85.0)$ & $1(16.7)$ & \\
\hline Operative time (min) & $499.75 \pm 150.19$ & $534.17 \pm 171.51$ & 0.637 \\
\hline Estimated blood loss (mL) & $517.50 \pm 661.00$ & $1,100.00 \pm 1,056.41$ & 0.113 \\
\hline Fecal diversion & & & 1.000 \\
\hline Yes & $2(10.0)$ & $1(16.7)$ & \\
\hline No & $18(90.0)$ & $5(83.3)$ & \\
\hline No. of anastomosis & $1.5 \pm 1.0$ & $1.33 \pm 0.52$ & 0.701 \\
\hline No. of organ resected & $1.45 \pm 1.36$ & $1.83 \pm 0.75$ & 0.388 \\
\hline
\end{tabular}

Values are presented as mean \pm standard deviation or number (\%).

ASA PS, American Society of Anesthesiologists physical status; CTx, chemotherapy; WD, well differentiated; MD, moderately differentiated; PD, poorly differentiated; CEA, carcinoembryonic antigen; PCl, peritoneal cancer index; EBL, estimated blood loss.

investigating 420 patients underwent CRS and HIPEC, the mean operation time was 563 minutes and the mean hospital stay was
22 days, which was longer than this study.

In this study, mortality was $0 \%$ but morbidity was as high as 
88.5\%. However, complications of grade III or higher were low and usually mild complications occurred. Postoperative mortality was reported to be less than $1 \%$ in the high-volume center [20], and other studies reported up to $4 \%$ to $8 \%[17,21-24]$. CRS and HIPEC are highly skilled procedures, and the learning curve is high enough to require 100 to 140 cases compared to other procedures. Morbidity tends to decrease as the surgical experience accumulates, resulting in about $12 \%-52 \%$ morbidity $[19,25]$. In this study, morbidity was higher than other studies, but mortality was close to other high-volume centers.

HIPEC has the advantage of high cytotoxic effect on intra-abdominal metastatic tumor cells and less systemic cytotoxic effect compared with systemic chemotherapy [26], but it does not suggest it is harmless. The chemotherapeutic agent used in HIPEC is mitomycin $\mathrm{C}$, which is known to induce bone marrow suppression and nephrotoxicity when administered intraperitoneally [23], however, no associated complications were found in this study.

In this study, blood transfusion was associated with severity of complication. Baratti et al. [23] reported no association with severe complications and transfusions in patients undergoing CRS and HIPEC. However, Saxena et al. [27] reported that in 936 patients undergoing CRS and HIPEC, more than 5 units of allogenic blood transfusion increased hospital mortality and morbidity above grade III. However, this study did not show any correlation with those who received more than 5 units of blood transfusion. The mechanism of transfusion-related complications was strongly correlated with the biological effect associated with transfusionrelated immunomodulation, and that the soluble mediator stored prior to transfusion may also cause posttransfusion complications [28]. In patients receiving transfusions, it was reported that alloantigens in donor cells can lead to cytokine mediators and induce cellular responses that affect inflammatory mediators, which cause complications due to change of immune system [29]. Therefore, to reduce the postoperative severe complications incidence, it is necessary to try to reduce the transfusion such as minimizing intraoperative bleeding and avoiding unnecessary transfusion.

The limitations of this study are as follows. First, it was a small retrospective study. Second, CRS and HIPEC were first performed in 2008, but since 2017, the research has been conducted in earnest and no significant factors related to the survival rate have been identified. Third, there was a selection bias in patient.

In conclusion, CRS and HIPEC are the treatments that are still being studied. However, complication incidence is high and highly skilled procedure are required. However, this can be overcome through intensive training and the accumulation of continuous surgical experience.

\section{CONFLICT OF INTEREST}

No potential conflict of interest relevant to this article was reported.

\section{ACKNOWLEDGMENTS}

This work was supported by a National Cancer Center Grant (grant number: 1810191).

\section{REFERRENCES}

1. Elferink MA, de Jong KP, Klaase JM, Siemerink EJ, de Wilt JH. Metachronous metastases from colorectal cancer: a populationbased study in North-East Netherlands. Int J Colorectal Dis 2015; 30:205-12.

2. Sugarbaker PH, Landy D, Jaffe G, Pascal R. Histologic changes induced by intraperitoneal chemotherapy with 5 -fluorouracil and mitomycin $\mathrm{C}$ in patients with peritoneal carcinomatosis from cystadenocarcinoma of the colon or appendix. Cancer 1990;65: 1495-501.

3. Sugarbaker PH. Peritonectomy procedures. Ann Surg 1995;221: 29-42.

4. Kuijpers AM, Mirck B, Aalbers AG, Nienhuijs SW, de Hingh IH, Wiezer MJ, et al. Cytoreduction and HIPEC in the Netherlands: nationwide long-term outcome following the Dutch protocol. Ann Surg Oncol 2013;20:4224-30.

5. Elias D, Lefevre JH, Chevalier J, Brouquet A, Marchal F, Classe $\mathrm{JM}$, et al. Complete cytoreductive surgery plus intraperitoneal chemohyperthermia with oxaliplatin for peritoneal carcinomatosis of colorectal origin. J Clin Oncol 2009;27:681-5.

6. Désolneux G, Mazière C, Vara J, Brouste V, Fonck M, Béchade D, et al. Cytoreductive surgery of colorectal peritoneal metastases: outcomes after complete cytoreductive surgery and systemic chemotherapy only. PLoS One 2015;10:e0122816.

7. Canda AE, Sokmen S, Terzi C, Arslan C, Oztop I, Karabulut B, et al. Complications and toxicities after cytoreductive surgery and hyperthermic intraperitoneal chemotherapy. Ann Surg Oncol 2013;20:1082-7.

8. Kuijpers AM, Hauptmann M, Aalbers AG, Nienhuijs SW, de Hingh IH, Wiezer MJ, et al. Cytoreduction and hyperthermic intraperitoneal chemotherapy: the learning curve reassessed. Eur J Surg Oncol 2016;42:244-50.

9. Chua TC, Yan TD, Saxena A, Morris DL. Should the treatment of peritoneal carcinomatosis by cytoreductive surgery and hyperthermic intraperitoneal chemotherapy still be regarded as a highly morbid procedure?: a systematic review of morbidity and mortality. Ann Surg 2009;249:900-7.

10. Jafari MD, Halabi WJ, Stamos MJ, Nguyen VQ, Carmichael JC, Mills SD, et al. Surgical outcomes of hyperthermic intraperitoneal chemotherapy: analysis of the american college of surgeons national surgical quality improvement program. JAMA Surg 2014; 149:170-5.

11. Jacquet P, Sugarbaker PH. Clinical research methodologies in diagnosis and staging of patients with peritoneal carcinomatosis. Cancer Treat Res 1996;82:359-74.

12. Sugarbaker PH. Management of peritoneal metastases - Basic 
concepts. J BUON 2015;20 Suppl 1:S2-S11.

13. Koppe MJ, Boerman OC, Oyen WJ, Bleichrodt RP. Peritoneal carcinomatosis of colorectal origin: incidence and current treatment strategies. Ann Surg 2006;243:212-22.

14. Esquivel J. Current status of colorectal cancer with peritoneal carcinomatosis. Ann Surg Oncol 2010;17:1968-9.

15. Goéré D, Malka D, Tzanis D, Gava V, Boige V, Eveno C, et al. Is there a possibility of a cure in patients with colorectal peritoneal carcinomatosis amenable to complete cytoreductive surgery and intraperitoneal chemotherapy? Ann Surg 2013;257:1065-71.

16. Elias D, Gilly F, Boutitie F, Quenet F, Bereder JM, Mansvelt B, et al. Peritoneal colorectal carcinomatosis treated with surgery and perioperative intraperitoneal chemotherapy: retrospective analysis of 523 patients from a multicentric French study. J Clin Oncol 2010;28:63-8.

17. Glehen O, Gilly FN, Boutitie F, Bereder JM, Quenet F, Sideris L, et al. Toward curative treatment of peritoneal carcinomatosis from nonovarian origin by cytoreductive surgery combined with perioperative intraperitoneal chemotherapy: a multi-institutional study of 1,290 patients. Cancer 2010;116:5608-18.

18. Polanco PM, Ding Y, Knox JM, Ramalingam L, Jones H, Hogg $\mathrm{ME}$, et al. Institutional learning curve of cytoreductive surgery and hyperthermic intraperitoneal chemoperfusion for peritoneal malignancies. Ann Surg Oncol 2015; 22:1673-9.

19. Kusamura S, Baratti D, Deraco M. Multidimensional analysis of the learning curve for cytoreductive surgery and hyperthermic intraperitoneal chemotherapy in peritoneal surface malignancies. Ann Surg 2012;255:348-56.

20. Gusani NJ, Cho SW, Colovos C, Seo S, Franko J, Richard SD, et al. Aggressive surgical management of peritoneal carcinomatosis with low mortality in a high-volume tertiary cancer center. Ann Surg Oncol 2008;15:754-63.

21. Verwaal VJ, van Ruth S, de Bree E, van Sloothen GW, van Tinteren $\mathrm{H}$, Boot $\mathrm{H}$, et al. Randomized trial of cytoreduction and hy- perthermic intraperitoneal chemotherapy versus systemic chemotherapy and palliative surgery in patients with peritoneal carcinomatosis of colorectal cancer. J Clin Oncol 2003;21:3737-43.

22. Levine EA, Stewart JH 4th, Russell GB, Geisinger KR, Loggie BL, Shen P. Cytoreductive surgery and intraperitoneal hyperthermic chemotherapy for peritoneal surface malignancy: experience with 501 procedures. J Am Coll Surg 2007;204:943-53.

23. Baratti D, Kusamura S, Iusco D, Bonomi S, Grassi A, Virzì S, et al. Postoperative complications after cytoreductive surgery and hyperthermic intraperitoneal chemotherapy affect long-term outcome of patients with peritoneal metastases from colorectal cancer: a two-center study of 101 patients. Dis Colon Rectum 2014; 57:858-68.

24. Glehen O, Kwiatkowski F, Sugarbaker PH, Elias D, Levine EA, De Simone $\mathrm{M}$, et al. Cytoreductive surgery combined with perioperative intraperitoneal chemotherapy for the management of peritoneal carcinomatosis from colorectal cancer: a multi-institutional study. J Clin Oncol 2004;22:3284-92.

25. Moradi BN 3rd, Esquivel J. Learning curve in cytoreductive surgery and hyperthermic intraperitoneal chemotherapy. J Surg Oncol 2009;100:293-6.

26. Yan TD, Cao CQ, Munkholm-Larsen S. A pharmacological review on intraperitoneal chemotherapy for peritoneal malignancy. World J Gastrointest Oncol 2010;2:109-16.

27. Saxena A, Valle SJ, Liauw W, Morris DL. Allogenic blood transfusion is an independent predictor of poorer peri-operative outcomes and reduced long-term survival after cytoreductive surgery and hyperthermic intraperitoneal chemotherapy: a review of 936 cases. J Gastrointest Surg 2017;21:1318-27.

28. Vamvakas EC, Blajchman MA. Transfusion-related immunomodulation (TRIM): an update. Blood Rev 2007;21:327-48.

29. Kao KJ. Mechanisms and new approaches for the allogeneic blood transfusion-induced immunomodulatory effects. Transfus Med Rev 2000;14:12-22. 